Research article

\title{
The relationship between intercultural effectiveness and intercultural awareness and xenophobia among undergraduate nursing and vocational schools of health services students: A descriptive study
}

\author{
Serap Gungor ${ }^{\mathrm{a}}$, Betul Tosun ${ }^{\mathrm{b}, *}$, Mirko Prosen $^{\mathrm{c}}$ \\ ${ }^{a}$ Kahramanmaras Sutcu Imam University, Vocational School of Health Services, Bahcelievler Campus, Kahramanmaras, Turkey \\ ${ }^{\mathrm{b}}$ Hasan Kalyoncu University, Faculty of Health Sciences, Gaziantep, Turkey \\ ${ }^{\mathrm{c}}$ University of Primorska, Faculty of Health Sciences, Polje 42, 6310 Izola, Slovenia
}

\section{A R T I C L E I N F O}

\section{Keywords:}

Cultural awareness

Cultural competence

Cultural effectiveness

Intercultural

Health professionals

Nursing

Xenophobia

\begin{abstract}
A B S T R A C T
Background: Students who will become health professionals should be educated according to universal standards of providing foreign patients with culturally satisfying health care, free from discrimination.

Aim: This study aims to identify the relationship of intercultural effectiveness and awareness with xenophobia in undergraduate nursing students and vocational schools of health services students.

Method: This descriptive study was conducted with undergraduate nursing students $(N=257)$ and vocational schools of health services students $(N=341)$ in a region with a high refugee population in Turkey. Data were collected through the "Intercultural Awareness Scale," the "Intercultural Effectiveness Scale," and the "Xenophobia Scale."

Results: Of all the participants, $70.1 \%$ were females, and the mean age was $20.70 \pm 2.64$ years; $57 \%$ of the students were from the vocational school students, and $43 \%$ from the undergraduate nursing program. Female students had significantly higher scores in intercultural effectiveness, behavioral flexibility, xenophobia $(p=$ 0.036, $p=0.041, p=0.001$, respectively), interaction relaxation and interactant respect $(p<0.001, \mathrm{p}<0.001)$, while male students had significantly higher intercultural awareness $(\mathrm{p}<0.001)$. The median intercultural effectiveness score of the students living in the rural area was low $(p=0.044)$, and the median xenophobia score of the students who lived abroad was significantly lower $(p=0.032)$. There was a negative correlation between the Intercultural Effectiveness Scale total and Intercultural Awareness and Xenophobia Scale total mean scores (r $=-0.085, r=0.182$ ), and there was a weak, positive correlation between the Intercultural Awareness Scale total mean scores and the Xenophobia Scale mean scores $(r=0.113)$.

Conclusion: Intercultural sensitivity is considered to be improved by including course content in the curriculum to improve students' intercultural effectiveness and awareness levels and decrease their xenophobic prejudices.
\end{abstract}

\section{Introduction}

In the globalized world, factors such as natural disasters, wars, unemployment, desire for a better life, travel, health tourism, education, and political asylum have caused a rapid geographic mobility worldwide (Bilgiç and Sahin, 2019; Tosun and Sinan, 2020). As a result of this mobility, individuals take the features of their own culture to the places they go and form multicultural societies by interacting with the people there (Bulduk et al., 2017). The number of people who migrated to Turkey from other countries is reported to have increased by $17.2 \%$ since 2018 to 677,042 people in 2019 . Of these, 578,488 represented a foreign population ("TÜIK," 2020). As of December 2020, the number of registered Syrian people under temporary protection in Turkey is reported to be 3,639,572 ("RASAS," 2020).

Migrations in recent years have brought some positive concepts, such as the integration of foreign people, adaptation, and social integration, as well as some other negative concepts such as "xenophobia," defined as hating or being prejudiced toward people from other countries (Özmete et al., 2018). Increasing population mobility has necessitated the health care needs of people from various cultural and ethnic origins, and the concepts of cultural care which was defined for the first time in 1950s by Leininger, cultural competence and now the concept of

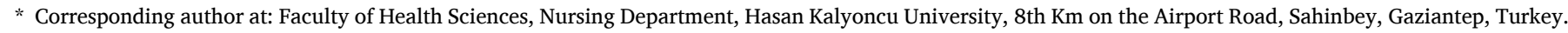

E-mail addresses: serap_32_06@hotmail.com (S. Gungor), betul.tosun@hku.edu.tr (B. Tosun), mirko.prosen@fvz.upr.si (M. Prosen).
} 
cultural safety has gained importance within the scope of the health care system and the education of nurses and other health professionals (Curtis et al., 2019; Mills et al., 2021; Saad Albougami et al., 2016). According to Campinha-Bacote (2011), cultural competence is the process of developing the ability to provide efficient, humane, and holistic care that includes five components: cultural awareness, cultural knowledge, cultural skills, cultural encounter, and cultural desire. Fundamental to the cultural concept of safety; on the other hand, are issues of social justice and the importance of power, prejudice and attitudes. This requires recognition of power disparities within the nursepatient relationship and at the level of social structures, policies and processes. Cultural safety is also achieved through nurses' cultural effectiveness and critical analysis of their own beliefs, attitudes and values and awareness that their culture and belief system may influence their interactions with patients and families (Curtis et al., 2019; Mills et al., 2021; Richardson et al., 2017; Saad Albougami et al., 2016).

All these explained concepts are interrelated and form a complex structure which addresses the commitment of health care professionals to deliver culturally sensitive care. The assumption that all people are culturally equal has negative consequences and makes it impossible to achieve the goals of treatment and quality health care. Failure of health care professionals to acknowledge the culture of the individual, family, or society can lead to communication breakdowns in health care settings, conflicts with patients, health care disparities, discrimination, racism, and stereotypical prejudice. Nurses and other health care professionals who are not trained in cultural safety and cultural competence cannot provide a culturally safe care environment and experience conflicts, cannot understand the reasons for these conflicts, and the conflicts deepen. This negatively impacts health outcomes and the satisfaction of care (Byrne, 2020; Curtis et al., 2019; Parisa et al., 2016).

Studies have reported that students in the field of health care are not competent regarding cultural approaches in patient care and have difficulties providing care to individuals from cultures different than theirs (Licen et al., 2021; Prosen, 2015; Tosun and Sinan, 2020). Also, some studies in the literature emphasize that different socio-demographic characteristics and cultural backgrounds of different student groups have an impact on cultural awareness, cultural effectiveness, and xenophobic behaviors (Bulduk et al., 2017; Tosun and Sinan, 2020; Tuncel and Aricioglu, 2018). Educators should therefore be aware that developing culturally competent health care professionals is not just about teaching a particular course, but rather about navigating a complex process that includes social, economic, political, demographic, individual experience, and emotional components (Byrne, 2020; Curtis et al., 2019; Gonzales, 2017; Koç et al., 2018).

The development of intercultural competence, the increase in cultural awareness, and the decrease in prejudices and xenophobic approaches could be made dynamic by providing continuous education on cultural safety and intercultural differences (Liu et al., 2018; Mills et al., 2021). In addition, understanding the health care providers' perceptions of health and illness and how they respond to them, as well as identifying their prejudices and habits that underlie their behaviors, is critical to promoting quality health care services (Claeys et al., 2020; Curtis et al., 2019; Parisa et al., 2016; Tosun and Sinan, 2020). Despite an increase in recent years, studies conducted in this context are limited. The findings of this study have a significant role in reviewing the efficiency of training curriculum and providing evidence on factors associated with the concepts of intercultural awareness, intercultural effectiveness, and xenophobia.

\subsection{Objectives}

The aim of this study is to examine the relationship between intercultural effectiveness, intercultural awareness, and xenophobia among undergraduate nursing students and vocational school students in Turkey. In this descriptive study, answers were sought to the following research questions;
- What is the level of cultural awareness and xenophobia among nursing students and vocational school students in a region where refugees live and receive health care?

- What is the difference between nursing students and vocational school students in terms of levels of cultural awareness and xenophobia?

- What is the difference between the levels of cultural awareness, cultural efficacy and xenophobia depending on the sociodemographic and other characteristics of the students?

- What is the relationship between students' cultural awareness, cultural efficacy and xenophobia levels?

\section{Methods}

\subsection{Study design}

A descriptive cross-sectional design was used.

\subsection{Setting and sample}

The study was conducted among undergraduate nursing students and vocational schools of health services students in two universities located in the Southeastern Anatolia region of Turkey, which is heavily populated by refugees. The target population were students in academic year 2019/2020 enrolled in the undergraduate nursing students $(N=$ 323 ) and vocational school students $(N=1000)$ enrolled in different study programs within the healthcare discipline (nurse assistant, elderly care technician, ambulance and emergency care technician, physiotherapy technician, medical documentation technician, anesthesia technician). In Turkey, undergraduate nursing programs last for eight semesters, and programs in vocational school students last for four semesters after high school graduation.

The sample size of the study was calculated considering the scale item numbers and recommendations in the literature (Özmete et al., 2018; Portalla and Chen, 2010; Yakar and Alpar, 2017). In addition, this study utilized the G*Power (version 3.1.9.2) program to calculate the sample size. It was anticipated that the students' Intercultural Effectiveness Scale mean scores would be analyzed according to the risk factors, and the difference between the two mean scores would be calculated using independent sample $t$-test in independent groups. Hence, when the effect size was taken as 0.3 , the alpha value as 0.05 , and theoretical power as $90 \%$, the number of students was determined as 506. Simple random sampling method was used; 300 undergraduate nursing students and 350 vocational school students were invited to the study, as it is thought that a request to fill in online questionnaires would not be answered. The sample size consisted of undergraduate nursing students 257 , vocational school students 341 , total students 598 (45.2\% of the totally population) who agreed to participate in the study.

\subsection{Data collection}

The study, which was designed as a self-administered online survey, was conducted in February and March 2020. After approval of the study, the link to the questionnaire was distributed through email to all eligible participants. Participants completed the survey via Google Forms, a secure online survey platform.

\subsection{Measurements}

The questionnaire consisted of four parts: (1) sociodemographic characteristics, (2) the Intercultural Awareness Scale, (3) the Intercultural Awareness Scale, and (4) the Xenophobia Scale.

\subsubsection{The Intercultural Awareness Scale}

The Intercultural Awareness Scale, developed by Rozaimie et al. (2011) is composed of nine items that measure cultural awareness. 
Turkish reliability and validity of the scale were performed by Yakar and Alpar (2017). The scale was adapted to the Turkish culture as a onedimensional scale, and the scores ranged between 9 and 45. Lower scores obtained from the scale indicate that individuals have intercultural awareness. While Cronbach's alpha value of the scale was found as 0.73 in the study conducted by Yakar and Alpar (2017), this study found Cronbach's alpha value as 0.75 .

\subsubsection{The Intercultural Effectiveness Scale}

The Intercultural Effectiveness Scale was developed by Portalla and Chen (2010), Yakar and Alpar (2017) tested the reliability and validity of the Turkish version to measure the intercultural effectiveness of the nurses who provided care to individuals from different cultures. They reported Cronbach's alpha coefficient of the scale as 0.85 . The scale has six lower dimensions and consists of 24 items like the original scale. The factor analysis yielded a 20-item Intercultural Effectiveness Scale with six factors, including behavioral flexibility, interaction relaxation, interactant respect, message skills, identity maintenance, and interaction management. The scores obtained from the scale range between 20 and 100, and higher scores indicate higher intercultural effectiveness (Yakar and Alpar, 2017). This study found Cronbach's alpha value as 0.77 .

\subsubsection{The Xenophobia Scale}

The scale was developed by van der Veer et al. (2011). Turkish adaptation, reliability, and validity of the scale were performed by Özmete et al. (2018). The scale has 11 items with responses that use a six-point likert scale with options ranging from "I totally disagree (1)" to "I totally agree (6)". While items 1 to 10 are scored normally, the 11 th item is scored reversely. Özmete et al. (2018) indicated that the scores obtained from the Turkish Xenophobia Scale range between 11 and 66, with higher scores indicating higher xenophobia risk. For the participants, 11 points mean no xenophobia, 66 means the highest xenophobia, and scores higher than 40 points can be considered serious xenophobia (Özmete et al., 2018). This study found Cronbach's alpha value as 0.897 .

\subsection{Data analysis}

Data were analyzed in the SPSS for Windows 21.0 version statistical package program. Descriptive statistics included numbers, percentages, mean \pm Sd, and minimum-maximum values. Test of normality was done using the Shapiro-Wilk test. The comparison of the scale mean scores was done using the Mann-Whitney $U$ test to compare two groups and Kruskal Wallis Test analysis for the comparison of three or more groups. Mann-Whitney U test correction with advanced statistics was utilized to understand which groups caused differences in the case of the comparison of three or more groups. Spearman Correlation analyses were used to determine the relationship between scale mean scores. Statistical significance was defined at $p<0.05$.

\subsection{Ethical considerations}

We received research ethics committee approval from the Institutional Review Board (date 04 February 2020, number 2020/004) as well as written approval from both participating institutions. The study was conducted according to the principles of the Declaration of Helsinki. Before the study, the students were informed about the purpose of the study, and their verbal consent was received in line with the principle of voluntary participation. The students completed the questionnaires without indicating their names, and the forms were completed in 10 to $15 \mathrm{~min}$. All data were collected anonymously with no possible linking of IP addresses to surveys.

Permission to use the questionnaires was obtained from the authors who performed the reliability and validity of the Intercultural Awareness Scale and the Intercultural Effectiveness Scale and the Xenophobia Scale via e-mail.

\section{Results}

Of all the participants, $70.1 \%$ were females, and the mean age was $20.70 \pm 2.64$ years; $57 \%$ of the students were from the vocational school students, and $43 \%$ from the undergraduate nursing program. They lived the longest period in a city for $64.5 \%$, and $43.8 \%$ of the students met people from different cultures every day. Besides, $54.7 \%$ received education about transcultural health care, $79.3 \%$ wanted to participate in education programs about transcultural health care, $35.6 \%$ communicated with people from different countries through social media, and $64.7 \%$ wanted to work abroad (Table 1). The Intercultural Awareness Scale total mean score of the participating students was $20.90 \pm 6.584$, the Intercultural Effectiveness Scale total mean score was $62.65 \pm 7.91$, and the Xenophobia Scale total mean score was $40.50 \pm 9.73$.

Female students had significantly higher scores in intercultural effectiveness, behavioral flexibility, xenophobia $(\mathrm{z}=-2.092, p=0.036$; $\mathrm{z}=-2047, p=0.041 ; \mathrm{z}=-3.335, p=0.001$ respectively), interaction relaxation, and interaction respect $(\mathrm{z}=-3.888, p<0.001 ; \mathrm{z}=-3.888, \mathrm{p}$ $<0.001$ ), while male students had significantly higher scores in intercultural awareness $(\mathrm{z}=-3.313, \mathrm{p}<0.001)$ (Table 2).

Those students who lived in rural areas had low median cultural effectiveness score $(\chi 2=8.123, p=0.044)$, and the xenophobia score median was low for the students who lived abroad $(\chi 2=8.772, p=$ 0.032). The identity management score median of the students who received education through transcultural health care was found to be significantly higher than those who did not $(\mathrm{z}=-2.250, p=0.024)$ (Table 2). Intercultural effectiveness $(z=-2.910, p=0.004)$, behavioral flexibility $(\mathrm{z}=-3.338, p=0.001)$, interaction relaxation $(\mathrm{z}=-2.167, p$ $=0.030)$, interactant respect $(\mathrm{z}=-2.167, \mathrm{p}=0.030)$, and interaction management $(\mathrm{z}=-1.982, p=0.048)$ levels of the students who wanted

Table 1

Descriptive characteristics of students $(N=598)$.

\begin{tabular}{|c|c|c|}
\hline Characteristics & $\mathrm{N}$ & $\%$ \\
\hline \multicolumn{3}{|l|}{ Gender } \\
\hline Female & 419 & 70.1 \\
\hline Male & 179 & 29.9 \\
\hline \multicolumn{3}{|l|}{ School/study programme } \\
\hline Undergraduate nursing students & 257 & 43.0 \\
\hline Vocational level students & 341 & 57.0 \\
\hline \multicolumn{3}{|l|}{ Place of residence } \\
\hline City & 386 & 64.5 \\
\hline Town & 128 & 21.4 \\
\hline Rural area & 76 & 12.7 \\
\hline Abroad & 8 & 1.3 \\
\hline \multicolumn{3}{|l|}{ Region } \\
\hline Southeastern Anatolia Region & 269 & 45.0 \\
\hline Mediterranean Region & 229 & 38.3 \\
\hline East Anatolian Region & 46 & 7.7 \\
\hline Black Sea Region & 4 & 0.7 \\
\hline Marmara Region & 13 & 2.2 \\
\hline Aegean Region & 7 & 1.2 \\
\hline Middle Anatolian Region & 11 & 1.8 \\
\hline \multicolumn{3}{|c|}{ Interaction with people from different cultures/countries } \\
\hline Every day & 262 & 43.8 \\
\hline Once a week & 119 & 19.9 \\
\hline Once a month & 85 & 14.2 \\
\hline One month less & 132 & 22.1 \\
\hline \multicolumn{3}{|c|}{ Received education about intercultural healthcare } \\
\hline Yes & 327 & 54.7 \\
\hline No & 271 & 45.3 \\
\hline \multicolumn{3}{|c|}{ Willing to participate in intercultural education } \\
\hline Yes & 474 & 79.3 \\
\hline No & 124 & 20.7 \\
\hline \multicolumn{3}{|c|}{$\begin{array}{l}\text { Use of social media for communication with people from other } \\
\text { countries }\end{array}$} \\
\hline Yes & 213 & 35.6 \\
\hline No & 385 & 64.4 \\
\hline \multicolumn{3}{|l|}{ Desire to work abroad } \\
\hline Yes & 387 & 64.7 \\
\hline No & 211 & 35.3 \\
\hline
\end{tabular}


Table 2

The Intercultural Effectiveness, Intercultural Awareness, and Xenophobia of scale scores according to some descriptive characteristics.

\begin{tabular}{|c|c|c|c|c|c|c|c|c|c|}
\hline \multirow[t]{2}{*}{ Characteristics } & \multirow{2}{*}{$\begin{array}{l}\text { Intercultural } \\
\text { effectiveness }\end{array}$} & \multirow{2}{*}{$\begin{array}{l}\begin{array}{l}\text { Behavioral } \\
\text { flexibility }\end{array} \\
\text { Median (IQR) }\end{array}$} & \multirow{2}{*}{$\begin{array}{l}\begin{array}{l}\text { Interaction } \\
\text { relaxation }\end{array} \\
\text { Median (IQR) }\end{array}$} & \multirow{2}{*}{$\begin{array}{l}\begin{array}{l}\text { Interactant } \\
\text { respect }\end{array} \\
\text { Median } \\
\text { (IQR) }\end{array}$} & \multirow{2}{*}{$\begin{array}{l}\text { Message } \\
\text { skills } \\
\begin{array}{l}\text { Median } \\
\text { (IQR) }\end{array}\end{array}$} & \multirow{2}{*}{$\begin{array}{l}\begin{array}{l}\text { Interaction } \\
\text { management }\end{array} \\
\text { Median } \\
\text { (IQR) }\end{array}$} & \multirow{2}{*}{$\begin{array}{l}\begin{array}{l}\text { Identity } \\
\text { maintenance }\end{array} \\
\text { Median (IQR) }\end{array}$} & \multirow{2}{*}{$\begin{array}{l}\text { Intercultural } \\
\text { awareness } \\
\text { Median } \\
\text { (IQR) }\end{array}$} & \multirow{2}{*}{$\begin{array}{l}\text { Xenophobia } \\
\text { Median } \\
\text { (IQR) }\end{array}$} \\
\hline & & & & & & & & & \\
\hline \multicolumn{10}{|l|}{ Gender } \\
\hline Female & $63.00(12.00)$ & $13.00(4.00)$ & $12.00(5.00)$ & $12.0(5.00)$ & $9.0(2.00)$ & $6.0(3.00)$ & $9.0(3.00)$ & $19.0(7.00)$ & $\begin{array}{l}42.0 \\
(14.00)\end{array}$ \\
\hline Male & $62.00(10.00)$ & $12.00(3.00)$ & $11.00(5.00)$ & $11.0(5.00)$ & $9.0(2.00)$ & $6.0(2.00)$ & $9.0(2.00)$ & $21.0(10.00)$ & $\begin{array}{l}37.0 \\
(15.00)\end{array}$ \\
\hline Test (z), & -2.092 & -2.047 & -3.888 & -3.888 & -0.343 & -0.523 & -0.581 & -3.313 & -3.335 \\
\hline $\mathrm{P}$ & $0.036^{*}$ & $0.041^{*}$ & $0.000^{* *}$ & $0.000^{* *}$ & 0.731 & 0.601 & 0.561 & $0.001^{* *}$ & $0.001^{\text {*** }}$ \\
\hline \multicolumn{10}{|c|}{ Place of residence } \\
\hline City $^{\mathrm{a}}$ & $63.0(11.25)$ & $13.0(4.00)$ & $12.0(5.00)$ & $12.0(5.00)$ & $9.0(2.00)$ & $6.0(3.00)$ & $9.0(3.00)$ & $20.0(9.00)$ & $\begin{array}{l}41.0 \\
(15.25)\end{array}$ \\
\hline Town $^{\mathrm{b}}$ & $63.5(13.00)$ & $13.0(2.75)$ & $12.0(5.00)$ & $12.0(5.00)$ & $9.0(2.00)$ & $6.0(3.00)$ & $9.0(2.75)$ & $19.0(7.75)$ & $\begin{array}{l}38.5 \\
(13.00)\end{array}$ \\
\hline Rural area $^{c}$ & $60.0(10.00)$ & $12.0(2.75)$ & $11.5(4.00)$ & $11.50(4.00)$ & $9.0(3.75)$ & $6.0(3.00)$ & $9.0(3.00)$ & $20.0(8.00)$ & $\begin{array}{l}39.5 \\
(14.75)\end{array}$ \\
\hline Abroad $^{\mathrm{d}}$ & $63.0(2.50)$ & $13.5(1.75)$ & $8.5(3.25)$ & $8.50(3.25)$ & $9.0(3.75)$ & $6.0(1.50)$ & $9.5(1.00)$ & $26.0(9.00)$ & $33.0(1.50)$ \\
\hline Test $(\chi 2)$, & 8.123 & 5.376 & 5.276 & 5.276 & 5.428 & 0.182 & 4.260 & 8.074 & 8.772 \\
\hline $\mathrm{P}$ & $\begin{array}{l}0.044^{*} \\
(c-a, b, d)\end{array}$ & 0.146 & 0.153 & 0.153 & 0.143 & 0.980 & 0.235 & 0.145 & $\begin{array}{l}0.032^{*} \\
(\mathrm{~d}-\mathrm{a}, \mathrm{b}, \mathrm{c})\end{array}$ \\
\hline \multicolumn{10}{|c|}{ Received education about intercultural healthcare } \\
\hline Yes & $64.0(11.00)$ & $12.0(3.00)$ & $12.0(5.00)$ & $12.0(5.00)$ & $9.0(2.00)$ & $6.0(3.00)$ & $9.0(3.00)$ & $20.0(9.00)$ & $\begin{array}{l}39.0 \\
(13.00)\end{array}$ \\
\hline No & $62.0(11.00)$ & $13.0(4.00)$ & $12.0(5.00)$ & $12.0(5.00)$ & $9.0(3.00)$ & $6.0(2.00)$ & $9.0(2.00)$ & $20.0(8.00)$ & $\begin{array}{l}41.0 \\
(16.00)\end{array}$ \\
\hline Test (z), & -1.789 & -0.573 & -0.221 & -0.221 & -1.622 & -0.704 & -2.250 & -0.657 & -0.929 \\
\hline $\mathrm{P}$ & 0.074 & 0.567 & 0.825 & 0.825 & 0.105 & 0.482 & $0.024^{*}$ & 0.511 & 0.353 \\
\hline \multicolumn{10}{|c|}{ Willing to participate in intercultural education } \\
\hline Yes & $63.0(12.00)$ & $13.0(4.00)$ & $12.0(5.00)$ & $12.0(5.00)$ & $9.0(2.00)$ & $7.0(3.00)$ & $9.0(2.00)$ & $20.0(8.00)$ & $\begin{array}{l}40.0 \\
(14.00)\end{array}$ \\
\hline No & $61.0(9.00)$ & $12.0(2.00)$ & $11.0(4.00)$ & $11.0(4.00)$ & $9.0(4.00)$ & $6.0(3.00)$ & $9.0(2.75)$ & $21.0(9.00)$ & $\begin{array}{l}40.0 \\
(14.75)\end{array}$ \\
\hline Test (z), & -2.910 & -3.338 & -2.167 & -2.167 & -0.180 & -1.982 & -1.120 & -1.828 & -0.056 \\
\hline $\mathrm{P}$ & $0.004 * *$ & $0.001^{* *}$ & $0.030^{*}$ & $0.030^{*}$ & 0.857 & $0.048^{*}$ & 0.263 & 0.068 & 0.956 \\
\hline \multicolumn{10}{|c|}{ Use of social media for communication with people from other countries } \\
\hline Yes & $64.0(15.00)$ & $13.0(3.00)$ & $12.0(5.00)$ & $12.0(5.00)$ & $9.0(2.00)$ & $6.0(2.00)$ & $9.0(3.00)$ & $21.0(10.00)$ & $\begin{array}{l}39.0 \\
(13.00)\end{array}$ \\
\hline No & $62.0(10.50)$ & $12.0(3.00)$ & $11.0(5.00)$ & $11.0(5.00)$ & $9.0(3.00)$ & $6.0(2.00)$ & $9.0(2.00)$ & $20.0(7.00)$ & $\begin{array}{l}41.0 \\
(15.00)\end{array}$ \\
\hline Test (z), & -2.603 & -0.039 & -0.528 & -0.528 & -0.835 & -2.249 & -1.273 & -2.674 & -0.820 \\
\hline $\mathrm{P}$ & $0.009^{*}$ & 0.969 & 0.597 & 0.597 & 0.404 & $0.024 *$ & 0.203 & $0.008^{*}$ & 0.412 \\
\hline \multicolumn{10}{|c|}{ Desire to work abroad } \\
\hline Yes & $63.0(13.00)$ & $12.0(3.00)$ & $12.0(5.00)$ & $12.0(5.00)$ & $9.0(2.00)$ & $6.0(3.00)$ & $9.0(3.00)$ & $19.0(9.00)$ & $\begin{array}{l}40.0 \\
(14.00)\end{array}$ \\
\hline No & $62.0(9.00)$ & $13.0(3.00)$ & $12.0(5.00)$ & $12.0(5.00)$ & $9.0(3.00)$ & $6.0(2.00)$ & $9.0(2.00)$ & $21.0(8.00)$ & $\begin{array}{l}41.0 \\
(14.00)\end{array}$ \\
\hline Test (z), & -1.5750 & -0.2680 & -0.7550 & -0.7550 & -2.2920 & -2.4160 & -1.5640 & -2.4510 & -1.1180 \\
\hline $\mathrm{P}$ & .115 & .788 & .450 & .450 & $.022 *$ & $.016^{*}$ & .118 & $.014^{*}$ & .264 \\
\hline \multicolumn{10}{|c|}{ Interaction with people from different cultures/countries } \\
\hline Every day & $63.00(12.00)$ & $13.0(4.00)$ & $12.0(5.00)$ & $12.0(5.00)$ & $9.0(3.00)$ & $6.0(3.00)$ & $9.0(3.00)$ & $20.5(8.00)$ & $\begin{array}{l}41.0 \\
(16.00)\end{array}$ \\
\hline Once a week & $63.00(11.00)$ & $13.0(2.00)$ & $11.0(5.00)$ & $11.0(5.00)$ & $9.0(3.00)$ & $6.0(2.00)$ & $9.0(2.00)$ & $19.0(9.00)$ & $\begin{array}{l}39.0 \\
(13.00)\end{array}$ \\
\hline Once a month & $64.00(12.00)$ & $12.0(3.00)$ & $11.0(5.00)$ & $11.0(5.00)$ & $9.0(2.00)$ & $7.0(2.00)$ & $9.0(2.00)$ & $19.0(8.00)$ & $\begin{array}{l}41.0 \\
(15.50)\end{array}$ \\
\hline $\begin{array}{l}\text { One month } \\
\text { less }\end{array}$ & $61.50(12.75)$ & $12.0(3.00)$ & $12.0(5.00)$ & $12.0(5.00)$ & $9.0(2.00)$ & $7.0(3.00)$ & $9.0(3.00)$ & $20.00(9.75)$ & $\begin{array}{l}39.0 \\
(13.75)\end{array}$ \\
\hline Test $(\chi 2)$, & 1.302 & 3.129 & 0.869 & 0.869 & 2.886 & 4.227 & 2.706 & 1.333 & 3.164 \\
\hline $\mathrm{P}$ & 0.729 & 0.372 & 0.833 & 0.833 & 0.410 & 0.238 & 0.439 & 0.721 & 0.367 \\
\hline
\end{tabular}

Notes. $\chi 2=$ Kruskal Wallis Test, $\mathrm{z}=$ Mann-Whitney $U$ test, IQR $=$.

* $\mathrm{p}<0.05$.

*** $\mathrm{p}<0.001$.

to receive education through health care were significantly higher. Intercultural effectiveness was significantly higher in students who positively replied to the question of "Do you communicate with people from other countries in social media?" Message skills $(\mathrm{z}=-2.992, p=$ 0.022), interaction management $(\mathrm{z}=-2.249, p=0.024)$, and intercultural awareness levels $(\mathrm{z}=-2.451, p=0.014)$ were significantly higher in students who wanted to work abroad (Table 2).

The comparison of the scale scores of the vocational school students and undergraduate nursing students according to their class year showed statistically significant differences between intercultural 
effectiveness ( $\chi 2=16.070, p=0.007)$, interactant respect $(\chi 2=20.105$, $p=0.001)$, intercultural awareness $(\chi 2=15.767, p=0.008)$, and xenophobia $(\chi 2=17.161, p=0.004)$ scores. The differences were observable in first- and third-year undergraduate nursing students (Table 3).

The intercultural effectiveness level of the first- and third-year undergraduate nursing students was found to be lower compared to the second- and fourth-year students and second-year vocational school students. Interactant respect levels of the first- and third-year undergraduate nursing students were lower compared to the second- and fourth-year students and first- and second-year vocational school students. The xenophobia levels of first-year undergraduate nursing students were lower compared to the second- and fourth-year students and the first-year vocational school students (Table 3).

A negative, weak correlation was found between the Intercultural Effectiveness Scale total mean scores and the Intercultural Awareness Scale total mean scores $(\mathrm{r}=-0.085, p<0.05)$. A negative, weak correlation was found between the Xenophobia Scale total mean scores and the Intercultural Effectiveness Scale total mean scores $(r=-0.182, p<$ 0.001). A positive, yet weak correlation was found between the Intercultural Awareness Scale total mean score and the Xenophobia Scale mean score $(r=0.113, \mathrm{p}<0.05)$. The students' intercultural awareness was found to increase, and their xenophobia level was found to decrease with the increase in their intercultural effectiveness level (Table 4).

\section{Discussion}

This study, which aimed to identify the relationship of intercultural effectiveness and awareness with xenophobia in undergraduate nursing students and vocational school students $(N=568)$, found that the participating students had a medium level of intercultural awareness and intercultural effectiveness and a high level of xenophobia. Intercultural awareness perception was found to increase, and the level of xenophobia was found to decrease with the increase in the intercultural effectiveness level. The fact that Turkey has a multicultural structure, that there are many refugees living in the region where the research was conducted, and that the refugees from Syria are innocent Muslim people fleeing the war, reinforce their acceptance. For this reason, it can be considered usual for the all students to have a medium level of intercultural effectiveness and intercultural awareness (Karatay et al., 2016; Kuru Alici, 2021). However, the increase in the number of refugees, the prolongation of their stay, the recent economic and social problems, the thought that refugees have deepened these problems, combined with the future anxiety of especially young university students and may have led to an increase in xenophobic thoughts (Tosun and Sinan, 2020). It is considered that it is inevitable and urgent to be aware of this danger and to take measures to prevent students from transferring these thoughts to their professional practices and cultural safety healthcare environment.

The majority of the students who participated in this study were females and had high levels of intercultural effectiveness, behavioral flexibility, interaction relaxation, interactant respect, and intercultural awareness; however, xenophobia perception levels of males were found to be lower. In a study conducted with university students, Gonzales (2017) found that male participants were emotionally more enduring in intercultural interaction than female participants and that women empathized culturally better than men. Karatas and Güzel (2020) conducted a study with university students enrolled in various departments and reported that men's xenophobia levels were higher than women's. An interesting finding of this study was that women's intercultural effectiveness and intercultural awareness were high, but their xenophobic thoughts were also high. As the majority of nurses and health professionals in Turkey are women, high numbers of foreign immigrants could be perceived as a threat to the current employment opportunities and thus as a possible difficulty in living conditions (Tosun and Sinan, 2020). So Higher xenophobia levels of females could be caused by female-dominant population of undergraduate nursing students and in the vocational school students.

Students who lived in rural areas were found to have lower intercultural effectiveness levels, and the xenophobia levels of students living abroad were low. It is somewhat expected that students who live in small, isolated communities, particularly those who do not encounter people from different cultures very often and do not have much knowledge about cultural differences, have low intercultural effectiveness levels and more prejudices toward different cultures (Bulduk et al.,

Table 3

Comparing the Intercultural Effectiveness, Intercultural Awareness and Xenophobia Scale medians of the class level of undergraduate nursing and vocational level students.

\begin{tabular}{|c|c|c|c|c|c|c|c|c|c|}
\hline & $\begin{array}{l}\text { Intercultural } \\
\text { effectiveness }\end{array}$ & $\begin{array}{l}\text { Behavioral } \\
\text { flexibility }\end{array}$ & $\begin{array}{l}\text { Interaction } \\
\text { relaxation }\end{array}$ & $\begin{array}{l}\text { Interactant } \\
\text { respect }\end{array}$ & $\begin{array}{l}\text { Message } \\
\text { skills }\end{array}$ & $\begin{array}{l}\text { Interaction } \\
\text { management }\end{array}$ & $\begin{array}{l}\text { Identity } \\
\text { maintenance }\end{array}$ & $\begin{array}{l}\text { Intercultural } \\
\text { awareness }\end{array}$ & Xenophobia \\
\hline & $\begin{array}{l}\text { Median } \\
\text { (IQR) }\end{array}$ & $\begin{array}{l}\text { Median } \\
\text { (IQR) }\end{array}$ & $\begin{array}{l}\text { Median } \\
\text { (IQR) }\end{array}$ & $\begin{array}{l}\text { Median } \\
\text { (IQR) }\end{array}$ & $\begin{array}{l}\text { Median } \\
\text { (IQR) }\end{array}$ & $\begin{array}{l}\text { Median } \\
\text { (IQR) }\end{array}$ & $\begin{array}{l}\text { Median } \\
\text { (IQR) }\end{array}$ & $\begin{array}{l}\text { Median } \\
\text { (IQR) }\end{array}$ & $\begin{array}{l}\text { Median } \\
\text { (IQR) }\end{array}$ \\
\hline \multicolumn{10}{|c|}{ Class level of undergraduate nursing and vocational level students } \\
\hline $\begin{array}{l}\text { 1st year } \\
\text { undergraudate } \\
\text { nursing students }\end{array}$ & $60.0(8.75)$ & $12.0(3.00)$ & $10.5(5.75)$ & $10.5(5.75)$ & $9.0(1.00)$ & $6.0(2.00)$ & $9.0(2.00)$ & $21.0(9.75)$ & $\begin{array}{l}35.5 \\
(14.50)\end{array}$ \\
\hline $\begin{array}{l}\text { 2nd year } \\
\text { undergraudate } \\
\text { nursing students }\end{array}$ & $64.0(12.75)$ & $13.0(3.75)$ & $12.5(5.00)$ & $12.5(5.00)$ & $9.0(3.00)$ & $6.0(3.00)$ & $9.0(3.00)$ & $20.0(9.00)$ & $\begin{array}{l}42.0 \\
(15.00)\end{array}$ \\
\hline $\begin{array}{l}\text { 3rd year } \\
\text { undergraudate } \\
\text { nursing students }\end{array}$ & $60.5(8.75)$ & $12.0(3.00)$ & $10.5(4.00)$ & $10.5(4.00)$ & $9.0(2.00)$ & $6.0(2.75)$ & $9.0(2.00)$ & $21.0(11.00)$ & $\begin{array}{l}37.0 \\
(11.75)\end{array}$ \\
\hline $\begin{array}{l}\text { 4th year } \\
\text { undergraudate } \\
\text { nursing students }\end{array}$ & $64.0(12.50)$ & $12.0(4.00)$ & $11.0(5.00)$ & $11.0(5.00)$ & $9.0(2.00)$ & $6.0(2.50)$ & $9.0(1.50)$ & $21.0(10.00)$ & $\begin{array}{l}43.0 \\
(13.50)\end{array}$ \\
\hline $\begin{array}{l}\text { 1st year vocational } \\
\text { level students }^{\mathrm{e}}\end{array}$ & $63.0(13.00)$ & $13.0(4.00)$ & $12.0(5.00)$ & $12.0(5.00)$ & $9.0(3.00)$ & $6.0(3.00)$ & $9.0(3.00)$ & $19.0(8.00)$ & $\begin{array}{l}42.0 \\
(13.00)\end{array}$ \\
\hline $\begin{array}{l}\text { 2nd year vocational } \\
\text { level students }\end{array}$ & $64.0(13.00)$ & $13.0(3.00)$ & $12.0(6.00)$ & $12.0(6.00)$ & $9.0(2.00)$ & $6.0(3.00)$ & $9.0(3.00)$ & $19.5(8.25)$ & $\begin{array}{l}40.0 \\
(16.50)\end{array}$ \\
\hline Test $(\chi 2)$ & 16.070 & 2.809 & 6.255 & 20.105 & 3.636 & 7.602 & 3.453 & 15.767 & 17.161 \\
\hline $\mathrm{P}$ & $\begin{array}{l}0.007^{*} \\
\text { (a-b,d) } \\
\text { (c-b,d) } \\
(\mathrm{f}-\mathrm{a}, \mathrm{c})\end{array}$ & 0.729 & 0.282 & $\begin{array}{l}0.001^{* *} \\
(\mathrm{~b}-\mathrm{a}, \mathrm{c}) \\
(\mathrm{a}-\mathrm{e}, \mathrm{f}) \\
(\mathrm{c}-\mathrm{e}, \mathrm{f})\end{array}$ & 0.603 & 0.180 & 0.630 & $\begin{array}{l}0.008^{*} \\
\text { (c-e) }\end{array}$ & $\begin{array}{l}0.004 \\
\text { (a-b,d) } \\
\text { (a-e) }\end{array}$ \\
\hline
\end{tabular}

\footnotetext{
${ }^{*} \mathrm{p}<0.05$

$p<0.001$.
} 
Table 4

The Intercultural Effectiveness, İntercultural awareness and Xenophobia Scale total mean score correlation.

\begin{tabular}{|c|c|c|c|c|c|c|c|c|c|}
\hline $\begin{array}{l}\text { Scales and } \\
\text { subscales }\end{array}$ & $\begin{array}{l}\text { Intercultural } \\
\text { effectiveness } \\
\text { (r) }\end{array}$ & $\begin{array}{l}\text { Behavioral } \\
\text { flexibility } \\
\text { (r) }\end{array}$ & $\begin{array}{l}\text { Interaction } \\
\text { relaxation } \\
(\mathrm{r})\end{array}$ & $\begin{array}{l}\text { Interactant } \\
\text { respect } \\
(\mathrm{r})\end{array}$ & $\begin{array}{l}\text { Message } \\
\text { skills } \\
\text { (r) }\end{array}$ & $\begin{array}{l}\text { Interaction } \\
\text { management } \\
\text { (r) }\end{array}$ & $\begin{array}{l}\text { Identity } \\
\text { maintenance } \\
\text { (r) }\end{array}$ & $\begin{array}{l}\text { Intercultural } \\
\text { awareness } \\
\text { (r) }\end{array}$ & $\begin{array}{l}\text { Xenophobia } \\
\text { (r) }\end{array}$ \\
\hline $\begin{array}{l}\text { Intercultural } \\
\text { effectiveness }\end{array}$ & 1 & & & & & & & & \\
\hline $\begin{array}{l}\text { Behavioral } \\
\text { flexibility }\end{array}$ & $0,532^{* *}$ & 1 & & & & & & & \\
\hline $\begin{array}{l}\text { Interaction } \\
\text { relaxation }\end{array}$ & $0,751^{* *}$ & $0,207^{* *}$ & 1 & & & & & & \\
\hline $\begin{array}{l}\text { Interactant } \\
\text { respect }\end{array}$ & $0,713^{* *}$ & $0,322^{* *}$ & $450^{* *}$ & 1 & & & & & \\
\hline Message skills & $0,452^{* *}$ & $0,238^{* *}$ & $0,184^{* *}$ & $0,086^{*}$ & 1 & & & & \\
\hline $\begin{array}{l}\text { Interaction } \\
\text { management }\end{array}$ & $0,648^{* *}$ & $0,203^{* *}$ & $0,587^{* *}$ & $0,383^{* *}$ & $0,203^{\text {*** }}$ & 1 & & & \\
\hline $\begin{array}{l}\text { Identity } \\
\text { maintenance }\end{array}$ & $0,507^{* *}$ & 0,238 ** & $0,255^{* *}$ & $0,237^{* *}$ & $0,348^{* *}$ & $0,178^{* *}$ & 1 & & \\
\hline $\begin{array}{l}\text { İntercultural } \\
\text { awareness }\end{array}$ & $-0,085^{*}$ & $-0,071$ & $-0,022$ & $-0,170^{* *}$ & $-0,079$ & 0,009 & $-0,042$ & 1 & \\
\hline Xenophobia & $-0,182^{* *}$ & $0,085^{*}$ & $-0,164 * *$ & $-0,289^{* *}$ & $-0,058$ & $0,125^{* *}$ & 0,053 & $0,113^{* *}$ & 1 \\
\hline
\end{tabular}

$\mathrm{r}=$ Correlation Coefficient, Spearman Correlation Test.

* $\mathrm{p}<0.05$.

$\mathrm{p}<0.001$.

2017; Tosun and Sinan, 2020; Tuncel and Aricioglu, 2018; Türker, 2019). Similarly, it is not surprising that students who have foreign country experience have higher awareness because such experience enables them to see and compare different cultures. Nearly half of the students met people from different cultures, and more than half of them wanted to work abroad. The intercultural awareness level of students who want to work abroad is higher. In another study, Tosun and Sinan (2020) similarly report that those who wanted to live abroad had higher intercultural awareness level and unprejudiced. The literature reports that students who go abroad through education programs have a better understanding of cultural differences (Allen et al., 2013; Özdemir, 2017; Türker, 2019).

More than half of the students in this study received education about intercultural healthcare, and a majority of them were willing to participate in education programs about transcultural healthcare. In recent years, cultural competent and cultural safety healthcare education has become necessary important in developing countries like Turkey (Balci and Ögüt, 2018; Curtis et al., 2019; Tuncel and Aricioglu, 2018). Therefore, it is of great importance to increase cultural awareness of the importance of intercultural nursing education and to prepare a standardized quality curriculum to address these issues (Chang et al., 2018; Prosen, 2015). The study revealed that students who received transcultural health care education had significantly higher identity management levels, and students who wanted to receive education through transcultural health care had higher levels of transcultural effectiveness, behavioral flexibility, interaction relaxation, and interaction management. The students who wanted to receive intercultural education and wanted to go abroad for education were reported to have higher awareness and learning desires about this issue (Koç et al., 2018). It is reported that an interdisciplinary approach using a variety of activities such as practice workshops/training or work/abroad training experiences for healthcare professionals is beneficial (Chen et al., 2020) and that only providing culturally-focused theoretical training approaches is not sufficient to reduce xenophobia behaviors and acquire cultural competence components (Limoges et al., 2019).

This study showed that intercultural effectiveness was higher in students who communicate with people from other countries in social media. Some studies found the intercultural awareness level is higher among individuals who communicate with peers from foreign countries (Carlson et al., 2017; Limoges et al., 2019). Carlson et al. (2017), also found that students who communicated with people from different cultures in social media had a higher level of cultural communication awareness. A number of factors, such as sharing culture-specific photos and videos on social media, communicating at a global level, making comments and reading others' comments on various topics, may have empowered students to learn about different cultures and thus increased students' cultural awareness levels.

The results indicated that intercultural effectiveness and intercultural awareness were low among first- and third-year undergraduate nursing students, while first-year undergraduate nursing students had low levels of xenophobia. Studies reporting similar results indicated that the intercultural effectiveness level of first-year students was low, and their intercultural effectiveness levels were positively affected by the intercultural care training and experiences throughout their education (Granel et al., 2021; Shaffer et al., 2019; Yakar and Alpar, 2017). In this study vocational school students had higher intercultural effectiveness compared to the undergraduate nursing students. This could be due to the fact that vocational school students start clinical practice education much earlier and frequently encounter more foreign patients in hospitals with high refugee populations. It is interesting that undergraduate nursing students, who are assumed to have a more comprehensive education, had lower intercultural effectiveness, intercultural awareness, and higher xenophobia levels, indicating that the education they receive on this issue is not effective.

A study conducted with last-year undergraduate nursing students reported that transcultural awareness was significantly affected by factors such as intercultural nursing skills, traveling abroad, and previous experiences Philips et al. (2017), which explains the high intercultural effectiveness and intercultural awareness levels of the fourth-year undergraduate nursing students and the second-year vocational school students in this study.

In this study last-year students, who are more educated about this topic than are those enrolled in lower years, have already become aware of the importance of patients' cultural characteristics regarding ethics and patient care, but they do not know how to respond to cultural differences and are not aware of discriminative behaviors. Besides, although this study was conducted in a region populated by a significant number of refugees, only half of the participating students reported having received education about cultural care. The quality of health service could be negatively affected by the prejudiced and negative approaches of nurses/other health professionals who are not welleducated or not equipped with knowledge about providing care to individuals, families, or groups from other cultures (Karatay et al., 2016; Tuncel and Aricioglu, 2018). Tosun and Sinan (2020) reported that undergraduate nursing students were prejudiced, particularly about providing care to refugees; some students thought nurses and 
institutions providing care to refugees should be separated, and some students had discriminative thoughts such as finding refugees rude toward health professionals and thinking that they did not obey the hospital rules. In addition, Karatay et al. (2016) reported that students had cultural awareness but did not know how culture affected health care practices. It is considered that the xenophobic thoughts of students who will become health professionals should be identified, and their negative ideas regarding this issue should be shaped based on the behaviors appropriate to health professionals.

\subsection{Limitations}

This study was conducted with students from one undergraduate nursing school and one vocational school students in a region where many refugees lived; therefore, students might have considered only refugees while answering questions about patients from different cultural backgrounds. Studies conducted with undergraduate nursing and vocational school students from different cultural backgrounds in different regions of Turkey could yield different results.

\section{Conclusion}

While almost half of the students stated that they received education about cultural care, high xenophobia scores indicate that they did not receive effective education. In line with these results, it is important to enhance the intercultural effectiveness and awareness levels of health professionals while they are still students. In addition, intercultural sensitivity is considered to be improved by including content to improve students' intercultural effectiveness and awareness levels and decrease their xenophobic prejudices in the course curriculum. Further steps include organizing activities that could bring students from different cultures together, increasing mutual interaction, and involving students in projects that enable them to work with patients from different cultures. Future health care professionals should follow the universal standards of providing patients of various cultural backgrounds with culturally satisfying health care free from discrimination.

\section{Source of funding}

This research received no specific grant from any funding agency in the public, commercial, or not-for-profit sectors.

\section{CRediT authorship contribution statement}

Serap Güngör: Conceptualization, Methodology, Software, Data curation, Writing - Original draft preparation Betül Tosun: Conceptualization, Methodology, Software, Data curation, Writing - Original draft preparation, Writing - Reviewing and Editing. Mirko Prosen: Methodology, Writing - Original draft preparation Visualization, Investigation, Writing - Reviewing and Editing.

\section{Declaration of competing interest}

The authors declare that they have no known competing financial interests or personal relationships that could have appeared to influence the work reported in this paper.

\section{References}

Allen, J., Brown, L., Duff, C., Nesbitt, P., Hepner, A., 2013. Development and evaluation of a teaching and learning approach in cross-cultural care and antidiscrimination in university nursing students. Nurse Educ. Today 33, 1592-1598. https://doi.org/ 10.1016/j.nedt.2012.12.006.

Balci, S., Ögüt, N., 2018. Some Determinants of the Intercultural Effectiveness Level: "A Survey on the Sample of Konya." https://doi.org/10.17719/jisr.2018.2466.

Bilgiç, S., Sahin, I., 2019. Intercultural sensitivity and ethnocentrism levels of nursing students. Suleyman Demirel Univ. J. Health Sci. https://doi.org/10.22312/ sdusbed.502408.
Bulduk, S., Usta, E., Dinçer, Y., 2017. Determination of intercultural sensitivity and influencing factors: an example of vocational School of Health. J. Duzce Univ. Health Sci. Inst. 7, 73-77.

Byrne, D., 2020. Evaluating cultural competence in undergraduate nursing students using standardized patients. Teach. Learn. Nurs. 15 https://doi.org/10.1016/j. teln.2019.08.010.

Campinha-Bacote, J., 2011. Delivering patient-centered care in the midst of a cultural conflict: the role of cultural competence. Online J. Issues Nurs. 16.

Carlson, E., Stenberg, M., Chan, B., Ho, S., Lai, T., Wong, A., Chan, E.A., 2017. Nursing as universal and recognisable: nursing students'perceptions of learning outcomes from intercultural peer learning webinars: a qualitative study. Nurse Educ. Today 57, 54-59. https://doi.org/10.1016/j.nedt.2017.07.006.

Chang, L., Chen, S.C., Hung, S.L., 2018. Embracing diversity and transcultural society through community health practicum among college nursing students. Nurse Educ. Pract. 31, 156-160. https://doi.org/10.1016/j.nepr.2018.05.004.

Chen, H.C., Jensen, F., Chung, J., Measom, G., 2020. Exploring faculty perceptions of teaching cultural competence in nursing. Teach. Learn. Nurs. 15, 1-6. https://doi. org/10.1016/j.teln.2019.08.003.

Claeys, A., Berdai-Chaouni, S., Tricas-Sauras, S., De Donder, L., 2020. Culturally sensitive care: definitions, perceptions, and practices of health care professionals. J. Transcult. Nurs. https://doi.org/10.1177/1043659620970625.

Curtis, E., Jones, R., Tipene-Leach, D., Walker, C., Loring, B., Paine, S.J., Reid, P., 2019. Why cultural safety rather than cultural competency is required to achieve health equity: a literature review and recommended definition. Int. J. Equity Health 18, 1-17. https://doi.org/10.1186/s12939-019-1082-3.

Gonzales, H.M., 2017. The intercultural effectiveness of university students. Psychology 08, 2017-2030. https://doi.org/10.4236/psych.2017.812129.

Granel, N., Leyva-Moral, J.M., Morris, J., Šáteková, L., Grosemans, J., BernabeuTamayo, M.D., 2021. Student's satisfaction and intercultural competence development from a short study abroad programs: a multiple cross-sectional study. Nurse Educ. Pract. 50, 102926 https://doi.org/10.1016/j.nepr.2020.102926.

Karatas, Z., Güzel, B., 2020. Examination of university students' attitudes towards xenophobia. J. Soc. Soc. Work 31, 500-523. https://doi.org/10.33417/tsh.641947.

Karatay, G., Bowers, B., Karadag, E.B., Demir, M.C., 2016. Cultural perceptions and clinical experiences of nursing students in eastern Turkey. Int. Nurs. Rev. 63, 547-554. https://doi.org/10.1111/inr.12321.

Koç, A., Öz, S., Kiliç, T., 2018. In: Investigation of Nursing Students ' Intercultural Sensitivity Level s and Related Factors, 3, pp. 1-15.

Kuru Alici, N., 2021. Cultural sensitivity and attitudes towards refugees of turkish nursing students: a cross sectional descriptive study. Int. J. Intercult. Relat. 80, 1-6. https://doi.org/10.1016/j.ijintrel.2020.10.011.

Licen, S., Karnjuš, I., Prosen, M., 2021. Measuring cultural awareness among slovene nursing student: a cross-sectional study. J. Transcult. Nurs. 32, 77-85. https://doi. org $/ 10.1177 / 1043659620941585$.

Limoges, J., Nielsen, K., MacMaster, L., Kontni, R., 2019. Globally networked learning: deepening Canadian and danish nursing students' understanding of nursing, culture and health. Nurse Educ. Today 76, 228-233. https://doi.org/10.1016/j. nedt.2019.02.006.

Liu, W., Stone, T.E., McMaster, R., 2018. Increasing undergraduate nursing students' cultural competence: an evaluation study. Glob. Health Res. Policy 3, 7. https://doi. org/10.1186/s41256-018-0062-2.

Mills, K., Creedy, D.K., Sunderland, N., Allen, J., 2021. Examining the transformative potential of emotion in education: a new measure of nursing and midwifery students' emotional learning in first peoples' cultural safety. Nurse Educ. Today 100, 104854. https://doi.org/10.1016/j.nedt.2021.104854.

Özdemir, E., 2017. Promoting EFL learners' intercultural communication effectiveness: a focus on Facebook. Comput. Assist. Lang. Learn. 30, 510-528. https://doi.org/ 10.1080/09588221.2017.1325907.

Özmete, E., Yildirim, H., Duru, S., 2018. Adaptation of the scale of xenophobia to Turkish culture: validity and reliability study. J. Soc. Policy Stud. 18, 191-209. https://doi. org/10.21560/spcd.v18i39974.451063.

Parisa, B., Reza, N., Afsaneh, R., Sarieh, P., 2016. Cultural safety : an evolutionary concept analysis. Holist. Nurs. Pract. 30, 33-38. https://doi.org/10.1097/ HNP.0000000000000125.

Philips, L., Bloom, T., Gainey, T., Chiocca, E., 2017. Influence of short-term study abroad experiences on community health baccalaureate students. J. Nurs. Educ. 56, 528-533. https://doi.org/10.3928/01484834-20170817-03.

Portalla, T., Chen, G.-M., 2010. The development and validation of the intercultural effectiveness scale Citation/Publisher attribution. Intercult. Commun. Stud. 19, 21-37.

Prosen, M., 2015. Introducing transcultural nursing education: implementation of transcultural nursing in the postgraduate nursing curriculum. Procedia Soc. Behav. Sci. 174, 149-155. https://doi.org/10.1016/j.sbspro.2015.01.640.

RASAS [WWW Document], 2020. Refug. Asylum Seek. Assist. Solidar. Assoc. URL. https $: / /$ multeciler.org.tr/turkiyedeki-suriyeli-sayisi/ (accessed 1.4.21)

Richardson, A., Yarwood, J., Richardson, S., 2017. Expressions of cultural safety in public health nursing practice. Nurs. Inq. 24, 1-10. https://doi.org/10.1111/ nin. 12171.

Rozaimie, A., Shuib, A., Ali, AJ., Oii, B., Siang, C., 2011. Multicultural awareness for better ways of life: a scale validation among Malaysian undergraduate students. In: 2nd International Conference on Business and Economic Research Proceeding, pp. 1174-1179. https://www.researchgate.net/publication/254399430. (Accessed 18 August 2021).

Saad Albougami, A., Pounds, K.G., Shaydeid Alotaibi, J., Nursing, I., 2016. In: International Archives of Nursing and Health Care Comparison of Four Cultural Competence Models in Transcultural Nursing: A Discussion Paper, 2, pp. 245-255. 
Shaffer, F., Bakhshi, M., Farrell, N., Álvarez, T., 2019. The role of nurses in advancing the objectives of the global compacts for migration and on refugees. Nurs. Adm. Q. 43, 10-18. https://doi.org/10.1097/NAQ.0000000000000328.

Tosun, B., Sinan, Ö., 2020. Knowledge, attitudes and prejudices of nursing students about the provision of transcultural nursing care to refugees: a comparative descriptive study. Nurse Educ. Today 85, 104294. https://doi.org/10.1016/j.nedt.2019.104294.

TÜIK [WWW Document], 2020. URL. https://data.tuik.gov.tr/Bulten/Index?p=Uluslara rasi-Goc-Istatistikleri-2019-33709 (accessed 1.4.21).

Tuncel, I., Aricioglu, A., 2018. The factors affecting the intercultural sensitivity perception level of psychological counseling and guidance students. Int. Educ. Stud. 11, 61. https://doi.org/10.5539/ies.v11n3p61.
Türker, A., 2019. Health Communication Competencies and Intercultural Effectiveness of Nurses and Midwives Working in Family Health Center. Marmara University.

van der Veer, K., Yakushko, O., Ommundsen, R., Higler, L., 2011. Cross-national measure of fear-based xenophobia: development of a cumulative scale. Psychol. Rep. 109, 27-42. https://doi.org/10.2466/07.17.PR0.109.4.27-42.

Yakar, H.K., Alpar, S.E., 2017. Determination of the reliability and validity of intercultural awareness and intercultural effectiveness scales. J. Hum. Sci. 14, 2748-2761. 